\title{
Cytotoxicity of Simvastatin in Human Breast Cancer MCF-7 and MDA-MB-231 Cell Lines
}

\author{
Andri Rezano ${ }^{1 *}$, Firda Ridhayanti², Athaya Riski Rangkuti², Taufik Gunawan ${ }^{3}$, \\ Gatot Nyarumenteng A Winarno ${ }^{4}$, Indra Wijaya ${ }^{5}$
}

\begin{abstract}
Objective: Statins, 3-hydroxy-3-methylglutaryl co-enzyme A (HMG-CoA) reductase inhibitors, have been shown to be effective in the treatment of cardiovascular disease. Recent reports demonstrate an anticancer effect induced by statins on lung and prostate cancer cells. The present study aimed to investigate the therapeutic potential of Simvastatin can serve as chemotherapeutic agent against human breast cancer MCF-7 and MDA-MB-231 cell lines. Methods: The cytotoxic effect of simvastatin against breast cancer cells were evaluated using MTT assay. The related mechanism of cell death was further determined by trypan blue staining, morphological changes observation, and drug combination index. Results: The results showed that simvastatin treatment substantially induced cell death in a dose-dependent and time-dependent manner on MCF-7 and MDA-MB-231 cells. Simvastatin exhibited a highly cytotoxic effect on MCF7 and MDA-MB-231 with half-maximal (50\%) inhibitory concentration $\left(\mathrm{IC}_{50}\right) 8.9 \mu \mathrm{M}$ and $4.5 \mu \mathrm{M}$ respectively. Consistently, we observed antiproliferative effect of Simvastatin was associated with apoptosis on breast cancer cell lines by determination of morphological changes. Moreover, this drug demonstrated a synergistic activity with doxorubicin on triggering cell death in MCF7 cells, but not in MDA-MB-231. Conclusion: Simvastatin has a potent cytotoxic effect resulting in the death of human breast cancer MCF-7 and MDA-MB-231 cell lines, demonstrating its potential as a new candidate for cancer drug.
\end{abstract}

Keywords: Simvastatin- cell death- breast cancer- antiproliferative- chemosensitive

Asian Pac J Cancer Prev, 22, Anticancer Activity of Natural Compounds: HOW's on Methods and Reports Suppl, 33-42

\section{Introduction}

Breast cancer is the second most common cancer in the world and is the most common cancer in women. Based on data from Globocan, the International Agency for Research on Cancer (IARC), it was reported that in 2018 there were 2,088,849 (11.6\%) new cases of breast cancer. Based on these data it is also mentioned that the number of breast cancer cases in Indonesia have the highest incidence when compared with other cancer cases, contributing up to 58,256 (16.7\%) new cases (Bray et al., 2018).

Breast cancer cells consist of several subtypes. The most common breast cancer is luminal subtype breast cancer with an ER-positive type. Luminal A subtype breast cancer is characterized by ER+, PR-, and HER2- (Perou and Borresen-Dale, 2011; Ostad and Parsa, 2011). Luminal A subtype breast cancer consists of MCF-7, T47D, and SUM185 cell lines. MCF-7 is the most commonly used breast cancer cell line in researches because it has very high hormone sensitivity due to its high ER expression (Holliday and Speirs, 2011). Other breast cancer cells are claudin-low (triple negative) subtypes that are similar to basal subtypes which are characterized by ER-, PR-, and HER2-. MDA-MB-231 is one of the claudin-low breast cancer subtype (Perou and Borresen-Dale, 2011; Ostad and Parsa, 2011).

To overcome the high incidence of breast cancer, the discovery and development of cancer treatments must continue to be attempted. Novel breast cancer drugs should have few side effects, greater therapeutic efficacy, and lower costs. The discovery of new cancer drugs is considered more effective when based on drugs that are already available. Research into possible beneficial effects of available drugs is more efficient than research on new herbal medicines because it has passed a series of standardized clinical trials. This will certainly affect the production time and research costs (Pantziarka et al., 2018).

${ }^{I}$ Department of Biomedical Sciences, Division of Cell Biology, Faculty of Medicine Universitas Padjadjaran, Bandung, Indonesia. ${ }^{2}$ Undergraduate Medical Program, Faculty of Medicine Universitas Padjadjaran, Indonesia. ${ }^{3}$ Biomedical Sciences Master Program, Faculty of Medicine Universitas Padjadjaran, Bandung, Indonesia. ${ }^{4}$ Department of Obstetrics and Gynecology, Faculty of Medicine, Padjadjaran University/Dr. Hasan Sadikin General Hospital, Bandung, Indonesia. ${ }^{5}$ Department of Internal Medicine, Faculty of Medicine Universitas Padjadjaran/Hasan Sadikin General Hospital, Bandung, Indonesia. *For Correspondence: andri.rezano@unpad.ac.id 
Statins are a class of HMG CoA reductase inhibitor drugs that have been clinically proven to treat dyslipidemia (Beckwitt et al., 2018). Currently approved statins by the FDA are atorvastatin, fluvastatin, lovastatin, pitavastatin, pravastatin, rosuvastatin, and simvastatin. Hypercholesterolemia's patients in Indonesia use statins as the first drug of choice. The most frequently prescribed statin for drug monotherapy is Simvastatin (42.8\%) (Munawar et al., 2013; Putra et al., 2017), which is cheaper than other types of statins (Moon and Bogle, 2006).

Based on its characteristics, statins are divided into lipophilic and hydrophilic types. Simvastatin itself is a type of lipophilic statin (Campbell et al., 2006); Feldt et al., 2015; Desai et al., 2015; Beckwitt et al., 2018). It has been reported (Fong, 2014), based on its hepatoselectivity, lipophilic statins tend to have higher exposure to non-liver tissue, whereas hydrophilic statins tend to be more hepatoselective. This occurs because lipophilic statins can be transported passively and non-selectively by diffusion into liver or non-liver tissue.

Statins have a major effect on reducing cholesterol concentrations (Hu et al., 2012; Cardwell et al., 2015). In addition, statins can also inhibit the growth of cancer cells through antiproliferative effects and cell death (Chan et al., 2003; Al-Husein et al., 2012; Gazzero et al., 2012; Wang et al., 2016; Wang et al., 2018). Colorectal cancer shows a non-significant apoptotic effect on statin drugs (Bardou et al., 2010). The administration of Simvastatin to lung and prostate cancer cells cause a significant apoptotic effect (Wang et al., 2018; Goc et al., 2012).

Based on the description above, Simvastatin has been shown to have a significant effect on apoptosis of lung and prostate cancer cells (Wang et al., 2018; Goc et al., 2012). Researchers suspect this is due to the inhibitory effect of proliferation and direct cell death due to the administration of Simvastatin (Beckwitt et al., 2018; Cardwell et al., 2015). Based on the description above, the author wants to evaluate the cytotoxic effects of Simvastatin and its effect on MCF-7 and MDA-MB-231 breast cancer cell lines' death.

\section{Materials and Methods}

\section{Chemicals and reagents}

RPMI 1640 medium (cat No. 11875093), fetal bovine serum (FBS) (cat No. 10270106) were purchased from Sigma-Aldrich, USA. L-glutamine (cat No. 25030164) and penicillin streptomycin (cat No. 15140122) were purchased from Thermo Fisher, USA. Simvastatin (cat No. S6196-5MG, Sigma Aldrich, USA) diluted with dimethylsulfoxide (DMSO, cat No. D8418, Sigma Aldrich, USA) at a concentration of $1 \mathrm{mM}$. 3-[4,5-dimethylthiazol2-yl]-2,5 diphenyl tetrazolium bromide (MTT) (cat No. M2128), were purchased from Sigma-Aldrich, USA. Doxorubicin was provided by Pharmacy of Hasan Sadikin General Hospital, Bandung, Indonesia. All the other chemicals were of analytical grade purchased from Merck, USA.

\section{Cell Culture}

The human breast cancer cells MCF-7 and
MDA-MB-231 cell lines were used to evaluate cytotoxic activity of Simvastatin. The MCF-7 cells were derived from Dr. Ahmad Faried and Prof. Hiroyuki Kuwano (Gunma University, Japan) which was obtained from American Type Culture Collection (ATCC, Manassas, Virginia). MDA-MB-231 cells were from Dr. Thordur Oskarsson (DKFZ, Germany). All cell lines were maintained in RPMI 1640 medium supplemented with $10 \%$ heat-inactivated FBS, 2 mM L-glutamine and 1\% penicillin/streptomycin in a humidified cell culture incubator that contained 5\% $\mathrm{CO} 2,21 \% \mathrm{O}_{2}, 37^{\circ} \mathrm{C}$. All experiments were conducted triplicate and from 3 different experiments at the Laboratory of Cell Culture and Cytogenetics, Faculty of Medicine, Universitas Padjadjaran, Indonesia.

\section{Cytotoxicity Assay (MTT Assay)}

Serial dilutions of Simvastatin were added into each of 96-well plates, then the cells were seeded at a density of $1 \times 10^{4}$ cells/well a day before treated with simvastatin concentrations of $0.5,1,3,5,10,20,50,75,100,125$, and $150 \mu \mathrm{M}$ and then incubated for 24,48 and 72 hours. After incubation, medium was removed, cytotoxic evaluation of Simvastatin against MCF-7 and MDA-MB-231 cancer cell lines were analyzed using MTT assay according to the protocol in previous studies (Rezano et al, 2013). The soluble formazan product was quantified using a micro-titer plate reader (Thermo Scientific- Multiscan EX, Singapore) at $550 \mathrm{~nm}$ and percentage of cell death was calculated using the following formula:

$\%$ cell death $=(1-($ average absorbance of triplicate drug wells)/(average absorbance of control wells))x 100\%

A dose-response curve was plotted into four parametric logistic models by Sigmaplot ver. 12 to enable the calculation of half-maximal (50\%) inhibitory concentration $\left(\mathrm{IC}_{50}\right)$ that kills MCF7 or MDA-MB-231 cells. The American National Cancer Institute guidelines set the $\mathrm{IC}_{50}$ cut off value for evaluating drug cytotoxic activity if less than $20 \mu \mathrm{M}$ after 48 and 72 hours incubation (Abdel-Hameed et al., 2012)

\section{Cell Death Percentage}

Determination of membrane integrity via trypan blue dye exclusion test was used to evaluate cell death and chemosensitivity against simvastatin and doxorubicin. Half-maximal inhibitory concentration of Simvastatin from MTT assay was used to set concentration course for cell death analysis. Cells were seeded on 6-well plates at density $5 \times 105$ cells/well prior treatment. Afterward, cells were treated with simvastatin ( $\mathrm{Sim}$ ) concentrations of 1 , 2, 5, 9, 30, $50 \mu \mathrm{M} ; 9 \mu \mathrm{M}$ Simvastatin $+5 \mu \mathrm{M}$ Doxorubicin (Sim9 and Dox5); 9 $\mu \mathrm{M}$ Simvastatin $+10 \mu \mathrm{M}$ Doxorubicin (Sim9 and Dox10) for MCF-7 cell line and 1, 2, 5, 9, $15,30,50 \mu \mathrm{M}$ Simvastatin; $5 \mu \mathrm{M}$ Simvastatin $+5 \mu \mathrm{M}$ Doxorubicin (Sim5 and Dox 5); $5 \mu \mathrm{M}$ Simvastatin $+10 \mu \mathrm{M}$ Doxorubicin (Sim5 and Dox10) for MDA-MB-231 cell line Both cell lines were then incubated for 48 hours and then the percentage of cell viability and cell death were calculated using the formula below: 

$\times 100 \%$

Cell Viability $(\%)=($ Viable Cell Count $) /($ Total Cell $)$

Cell Death $(\%)=($ Dead Cell Count $) /($ Total Cell $)$ $\times 100 \%$

\section{Morphological Analysis}

Observation of morphological changes of apoptotic cells after Simvastatin treatment was conducted as Moongkarndi et al., (2004) with slight modification. Using an inverted phase-contrast microscope (100X), cells changes such as cell shrinking, membrane blebbing, and ballooning were observed in predicting the apoptotic mechanism for cell death. Digital images were captured with camera connected with a computer and Toupview Software (version x64, 3.7.7892).

\section{Combination Index (CI)}

Cells were treated with different concentration of Simvastatin alone or in combination with Doxorubicin followed by the cytotoxic assay. As Chou (2010) reported in his previous work, Combination Index was analyzed with cell death percentage using Compusyn software.

\section{Statistical Analysis}

Statistical analysis was performed using SigmaPlot version 14.0 (SYSTAT Software Inc., USA), Compusyn, and IBM SPSS Statistics version 20 (SPSS Inc., USA). Analyzed data were obtained from three replications in two different experiments and presented as mean and standard deviation (mean \pm standard deviation). The cytotoxic effects of MCF-7 and MDA-MB-231 cell death from Simvastatin were analyzed by the four parametric logistic regression methods using SigmaPlot version 14.0. One-way ANOVA was conducted to determine the statistical significance $(\mathrm{P})$ of each difference between the control group and the treatment group. A P value of $<0.05$ indicates a statistically significant difference.
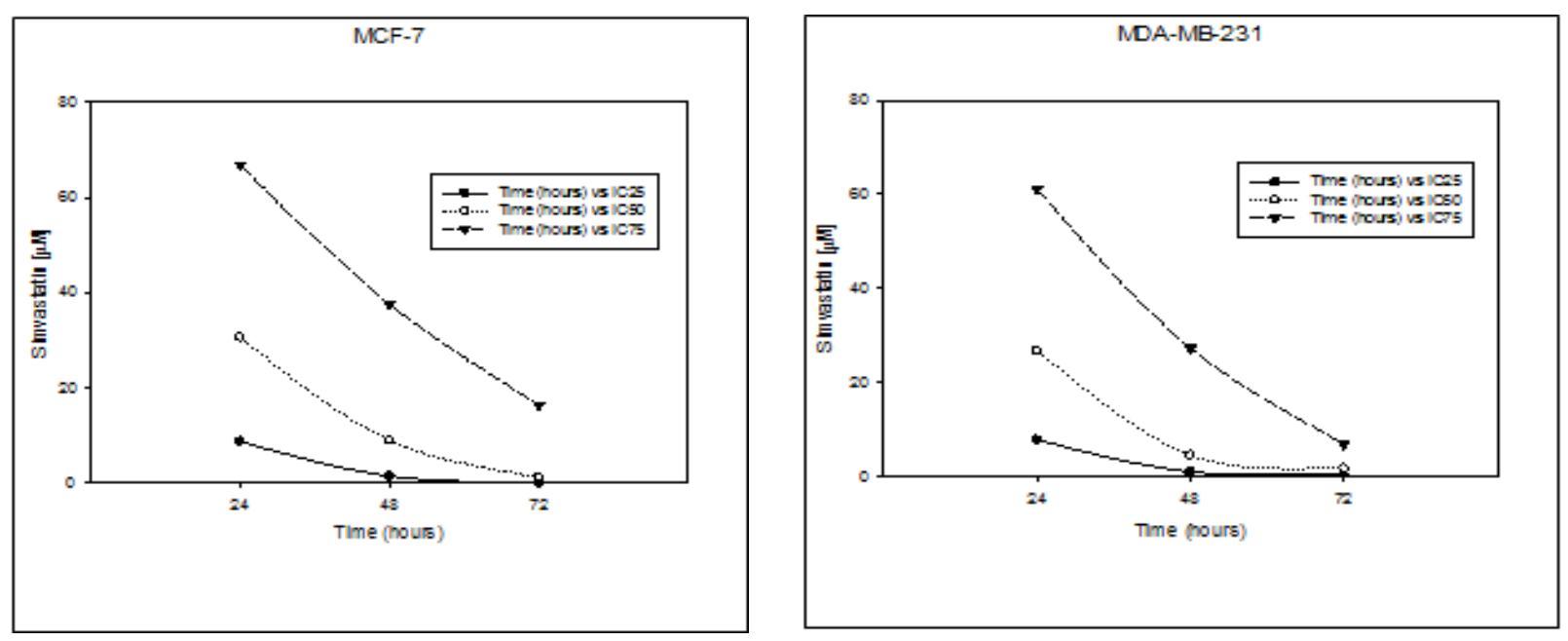

Figure 1. Graph of Time Relationships versus $\mathrm{IC}_{25}, \mathrm{IC}_{50}, \mathrm{IC}_{75}$ Simvastatin concentrations. Data were presented as mean and SD from triplicate data. Drug curves were created and $\mathrm{IC}_{50}$ of each cell lines were analyzed using four parametric logistic model by Sigmaplot ver.14. The graph shows the cell response to the time of administration of Simvastatin with concentrations of $\mathrm{IC}_{25}, \mathrm{IC}_{50}, \mathrm{IC}_{75}$ in the MCF-7 and MDA-MB-231 cell lines. 
Table 1. Percentage of MCF-7 and MDA-MB-231 Cell Death after Treated with Simvastatin and Doxorubicin for 24, 48, and 72 hours on MTT Assay

\begin{tabular}{|c|c|c|c|c|c|c|c|c|}
\hline \multirow[t]{3}{*}{ Drug } & \multirow[t]{3}{*}{ Dose $(\mu \mathrm{M})$} & \multicolumn{6}{|c|}{ Cell Death (\%) } & \multirow[t]{3}{*}{$P$-value } \\
\hline & & \multicolumn{3}{|c|}{ MCF-7 } & \multicolumn{3}{|c|}{ MDA-MB-231 } & \\
\hline & & 24 hours & 48 hours & 72 hours & 24 hours & 48 hours & 72 hours & \\
\hline \multirow[t]{12}{*}{ Simvastatin } & Control & 0 & 0 & 0 & 0 & 0 & 0 & \\
\hline & 0.5 & 18.2 & 14.3 & 41.8 & 8.3 & 22.6 & 25.6 & $<0.001$ \\
\hline & 1 & 15.3 & 18.7 & 46.3 & 11.6 & 31.4 & 41.3 & \\
\hline & 3 & 15.3 & 31.9 & 65 & 17.3 & 45.2 & 65.5 & \\
\hline & 5 & 25.1 & 40.4 & 66.1 & 18.4 & 54.3 & 72.3 & \\
\hline & 10 & 27.5 & 42.3 & 68.7 & 31.6 & 58.3 & 78.9 & \\
\hline & 20 & 31.7 & 51.1 & 69.8 & 39.8 & 73.4 & 81.6 & \\
\hline & 50 & 64.8 & 77.4 & 85.6 & 60.8 & 74.8 & 94.4 & \\
\hline & 75 & 85.3 & 81.9 & 96 & 92.9 & 90.6 & 97.4 & \\
\hline & 100 & 96.1 & 85.1 & 99.3 & 98.4 & 90.8 & 99.3 & \\
\hline & 125 & 101.9 & 88.7 & 99.9 & 100.6 & 91.6 & 99.4 & \\
\hline & 150 & 102.8 & 90.2 & 99.7 & 101.8 & 95.6 & 100.3 & \\
\hline \multirow[t]{2}{*}{ Doxorubicin } & 5 & 59 & 48.4 & 55.6 & 51.2 & 60.3 & 63.5 & $<0.001$ \\
\hline & 10 & 61.4 & 50.4 & 58.8 & 56.3 & 63.2 & 70.3 & \\
\hline
\end{tabular}

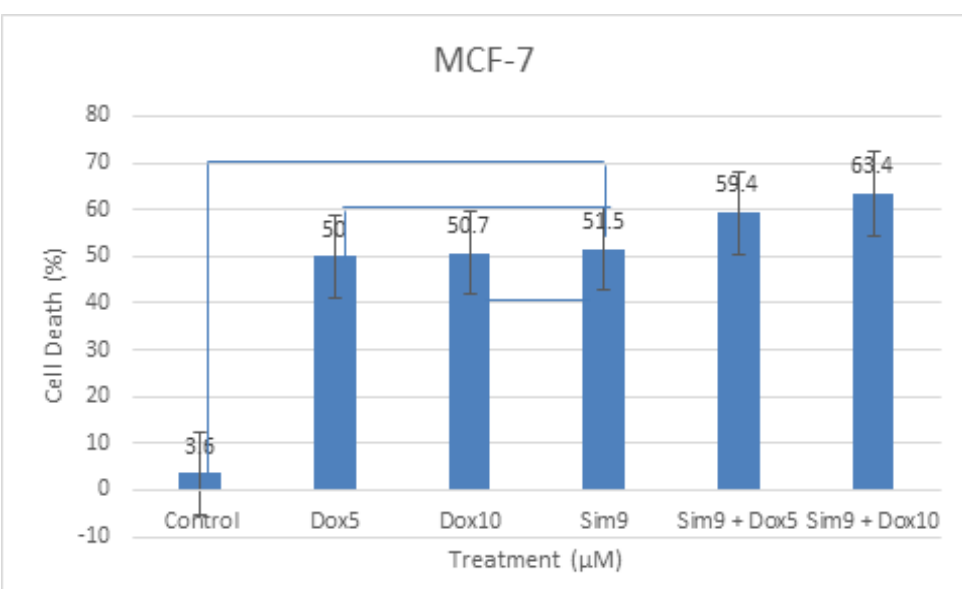

Figure 2. Cell Death Percentage with Various Concentration of Treatments and Its Significance Values. A significant effect of Simvastatin on MCF-7 breast cancer cell lines was demonstrated.

microscope and the results of cell changes were presented in Figure 5 (MCF-7) and Figure 7 (MDA-MB-231).

Simvastatin induces synergistic cell death with Doxorubicin in MCF-7

Our data showed a promising cytotoxic effect of Simvastatin by inducing cell death. Considering that cancer cells were activating multiple pathways for escaping from cell death. It is important to target cancer cells with conventional chemotherapy. Here, we evaluated combination effect of Simvastatin with Doxorubicin showed synergistic effect against MCF-7 with Combination Index were 0.34 for Sim 9 and Dox5; and 0.21 for Sim9 and Dox 10. The data suggested that Simvastatin can increase chemosensitivity of Doxorubicin in MCF-7 cells. However, Combination Index were not identical (CI>1) in MDA-MB-231 cells. The administration of drug dosages and the effects of combination treatment are presented in Figure 8 and Figure 9.

Table 2. $\mathrm{IC}_{25}, \mathrm{IC}_{50}$, and $\mathrm{IC}_{75}$ values in MCF-7 and MDA-MB-231 Breast Cancer Cells Treated with Simvastatin for 24, 48 , and 72 hours. Data obtained from three data replications in two different experiments $(\mathrm{P}<0.001)$.

\begin{tabular}{|c|c|c|c|c|c|c|}
\hline \multirow[t]{2}{*}{ Incubation Period (hour) } & \multicolumn{3}{|c|}{ MCF-7 } & \multicolumn{3}{|c|}{ MDA-MB-231 } \\
\hline & $\mathrm{IC}_{25}$ & $\mathrm{IC}_{50}$ & $\mathrm{IC}_{75}$ & $\mathrm{IC}_{25}$ & $\mathrm{IC}_{50}$ & $\mathrm{IC}_{75}$ \\
\hline 24 & $8.7 \mu \mathrm{M}$ & $30.6 \mu \mathrm{M}$ & $66.9 \mu \mathrm{M}$ & $7.8 \mu \mathrm{M}$ & $26.7 \mu \mathrm{M}$ & $61.2 \mu \mathrm{M}$ \\
\hline 48 & $1.4 \mu \mathrm{M}$ & $8.9 \mu \mathrm{M}$ & $37.6 \mu \mathrm{M}$ & $1.0 \mu \mathrm{M}$ & $4.5 \mu \mathrm{M}$ & $27.3 \mu \mathrm{M}$ \\
\hline 72 & $0.0 \mu \mathrm{M}$ & $1.1 \mu \mathrm{M}$ & $16.3 \mu \mathrm{M}$ & $0.4 \mu \mathrm{M}$ & $1.7 \mu \mathrm{M}$ & $6.8 \mu \mathrm{M}$ \\
\hline
\end{tabular}




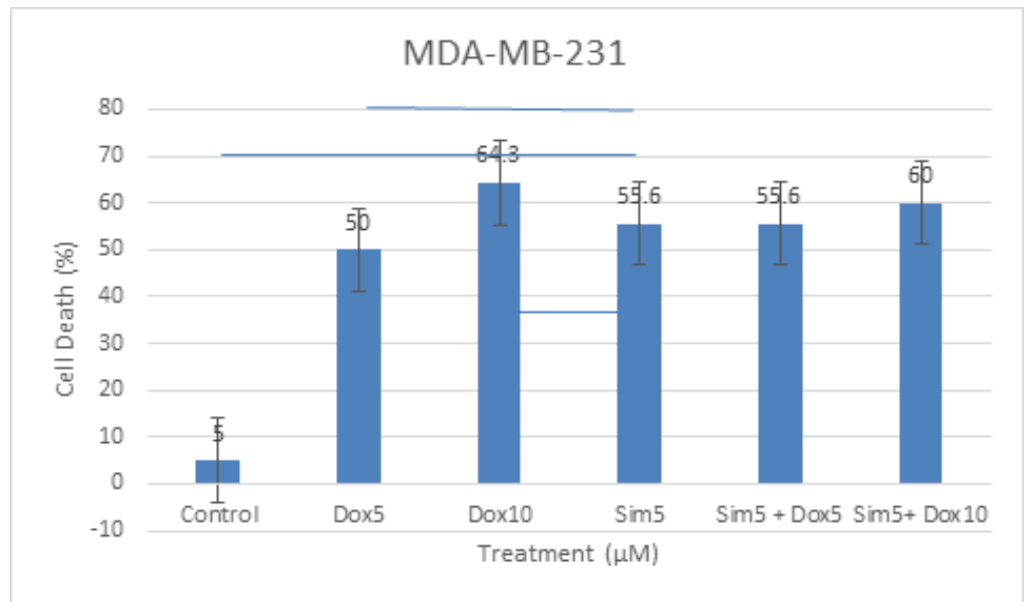

Figure 3. Cell Death Percentage with Various Concentration of Treatments and Its Significance Values. A significant effect of Simvastatin on MDA-MB-231 breast cancer cell lines was demonstrated.

\section{Discussion}

The use of statins as anticancer agents becomes an emerging interest due to their pleiotropic effects on various cells and tissues. Accumulating evidences suggests the beneficial effects of statins extend beyond their cholesterol-lowering properties. Preclinical data have shown antiproliferative, proapoptotic, anti-invasive and radiosensitizing properties of statins. In cancer patients, the efficacy of statins as anticancer agents have been evaluated both in monotherapy and in combination therapy. However, there are very limited studies on
Simvastatin for its anticancer activities. The effect of simvastatin in bladder cancer cell line reveals reduction of cell viability in a dose- and time- dependent manner but not induces apoptosis (Wang et al., 2016). Similarly, simvastatin treatment in human leukemic natural killer cell line demonstrates cell proliferation inhibition and cell cycle arrest at G2/M (Crosbie et al, 2013). Previous report from Ghavami et al., (2009), Simvastatin activates novel apoptotic pathway in primary human lung mesenchymal cells.

Here our data shows a promising anti-tumor activity of Simvastatin in breast cancer cells. The results
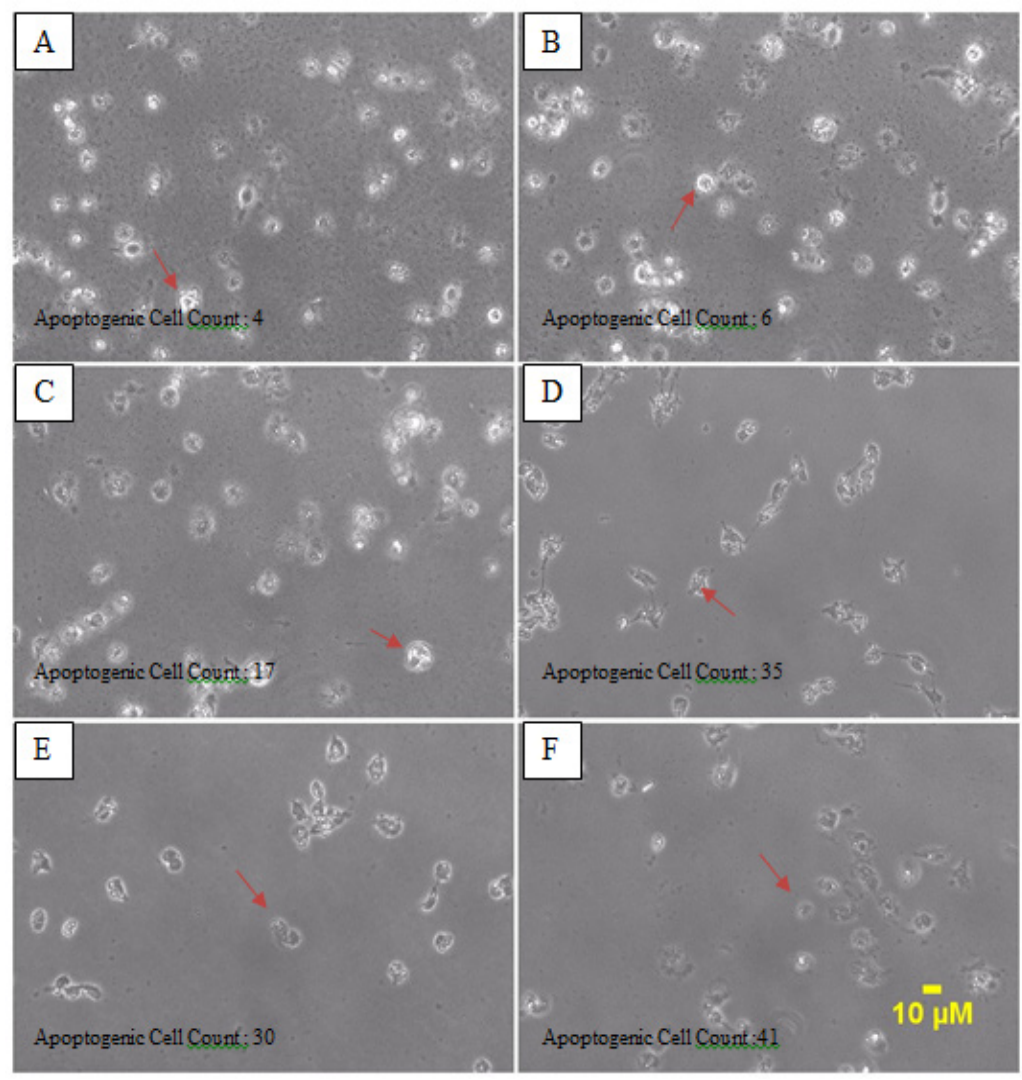

Figure 4. Morphological Studies by Inverted Microscope at Actual Magnification $100 \times$ on MCF-7. At concentration of Simvastatin (A) $1 \mu \mathrm{M}$, (B) $2 \mu \mathrm{M}$ and (C) $5 \mu \mathrm{M}$, intact MCF-7 breast cancer cell morphology were seen. At concentration of (D) $9 \mu \mathrm{M}$, (E) $30 \mu \mathrm{M}$, and (F) $50 \mu \mathrm{M}$, lysed MCF-7 breast cancer cell morphology were seen. 

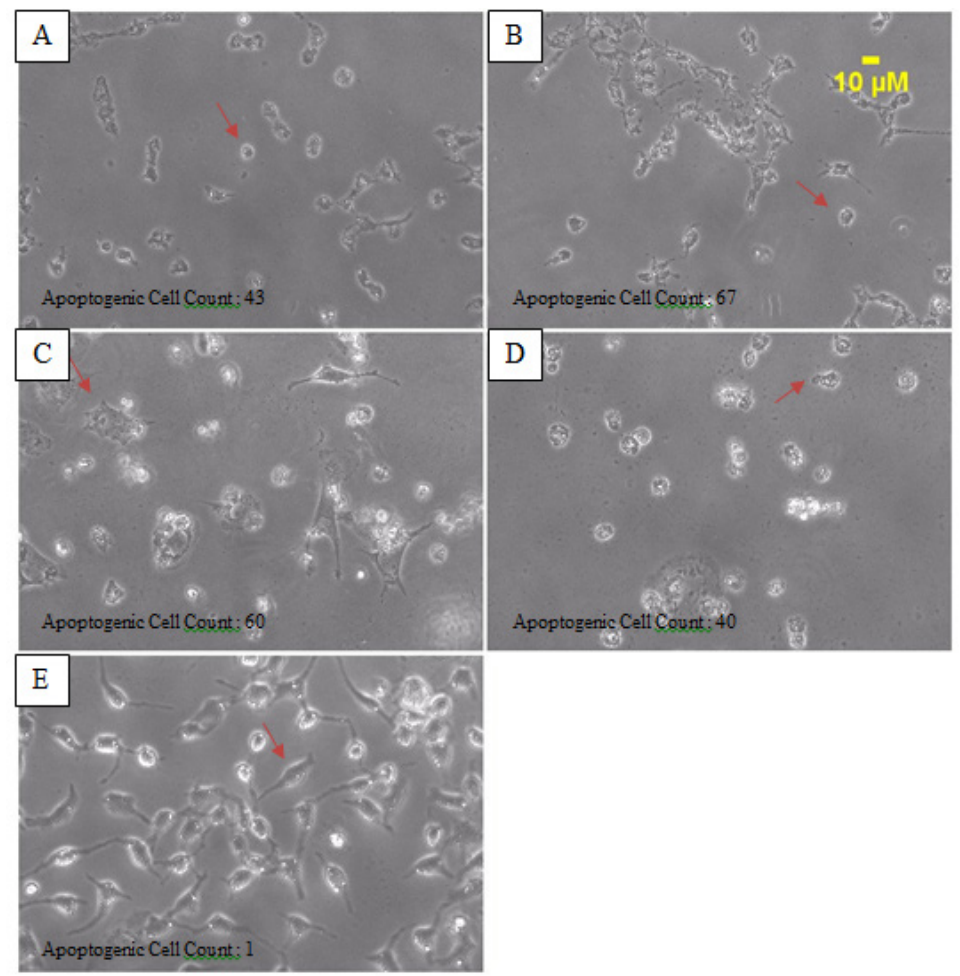

Figure 5. Morphological Studies by Inverted Microscope at Actual Magnification 100× on MCF-7. At a concentration of Simvastatin (A) $9 \mu \mathrm{M}$ Simvastatin $+5 \mu \mathrm{M}$ Doxorubicin, (B) $9 \mu \mathrm{M}$ Simvastatin $+10 \mu \mathrm{M}$ Doxorubicin, (C) $5 \mu \mathrm{M}$ Doxorubicin (positive control), and (D) $10 \mu \mathrm{M}$ Doxorubicin (positive control), lysed MCF-7 breast cancer cell morphology was seen. (E) Negative control of MCF-7 breast cancer cell lines were $80-90 \%$ confluent after incubation for 48 hours.

showed simvastatin has a cytotoxic effect on MCF-7 and MDA-MB-231 breast cancer cell lines. The results of this study proved that Simvastatin has a cytotoxic effect on MCF-7 and MDA-MB-231 breast cancer cell lines. Treatment of Simvastatin against these cell lines caused significant cell death $(\mathrm{P}<0.001)$ when compared

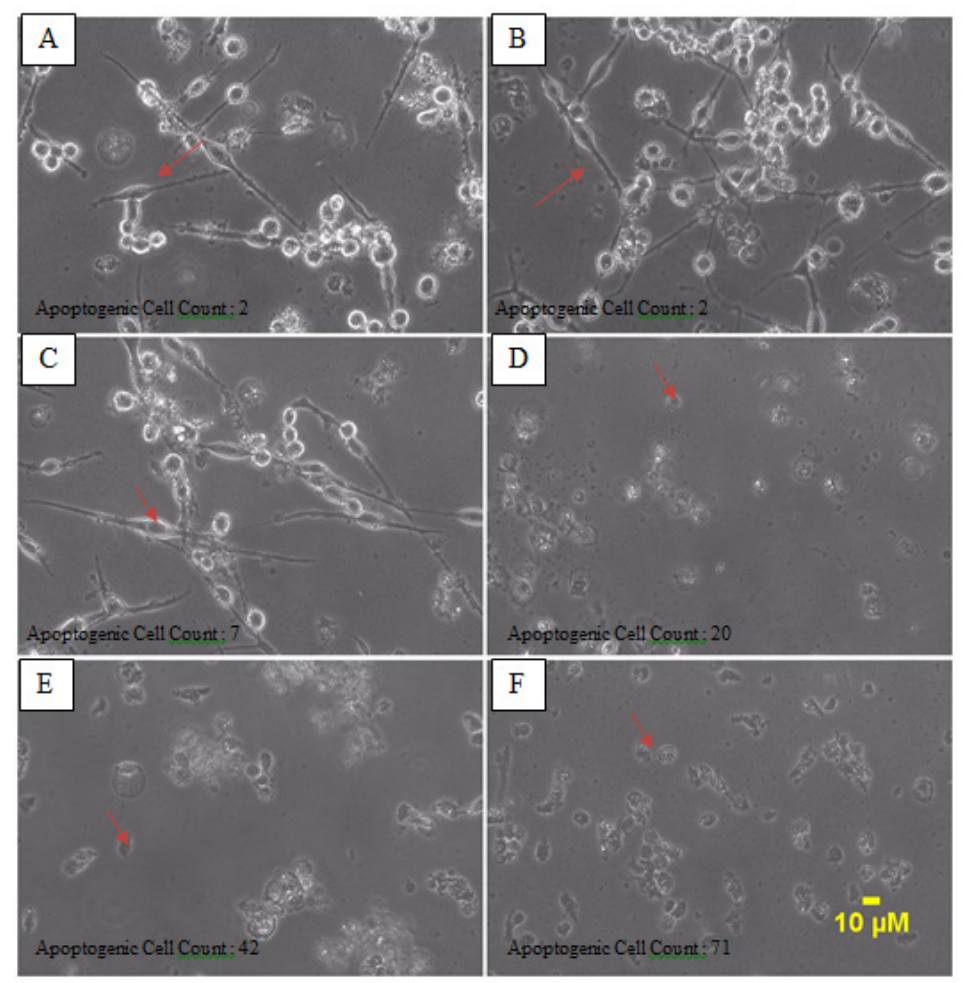

Figure 6. Morphological Studies by Inverted Microscope at Actual Magnification 100× on MDA-MB-231. At concentration of Simvastatin (A) $1 \mu \mathrm{M}$, (B) $2 \mu \mathrm{M}$, and (C) $5 \mu \mathrm{M}$, intact MDA-MB-231 breast cancer cell morphology was seen. At concentration of (D) $9 \mu \mathrm{M}$, (E) $15 \mu \mathrm{M}$, and (F) $30 \mu \mathrm{M}$, lysed MDA-MB-231 breast cancer cell morphology was seen. 

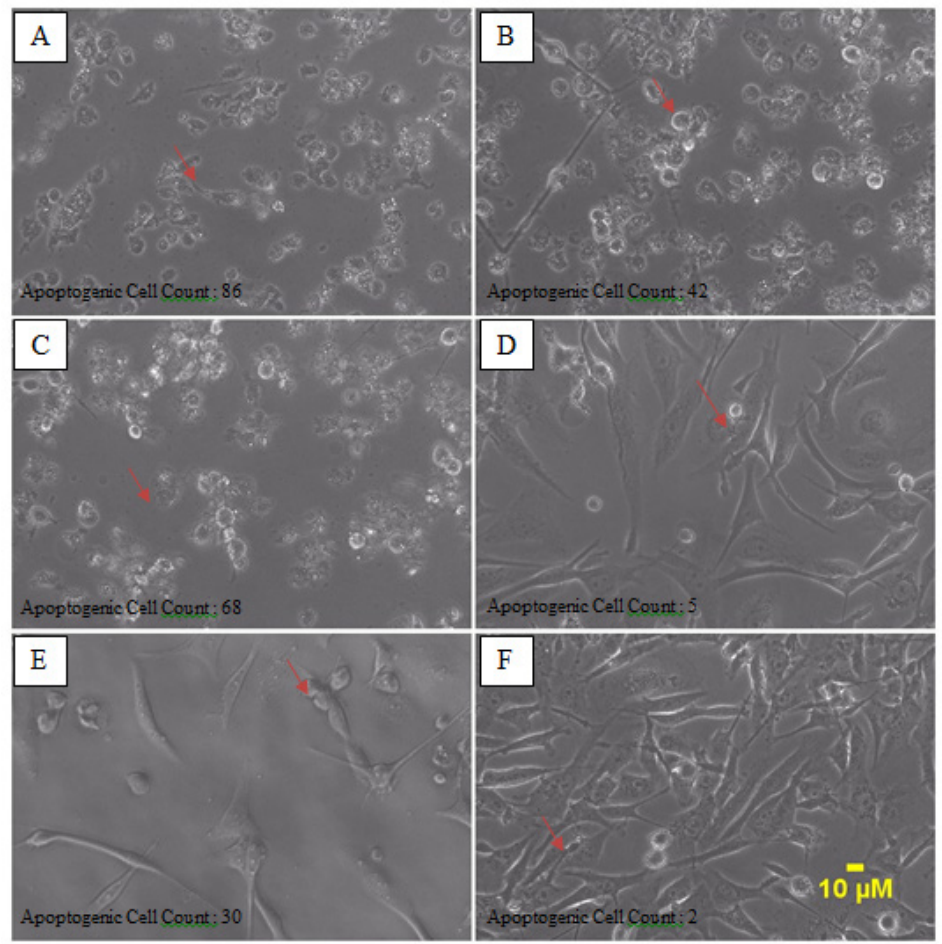

Figure 7. Morphological Studies by Inverted Microscope at Actual Magnification 100× on MDA-MB-231. At concentration of (A) $50 \mu \mathrm{M}$ Simvastatin, (B) $5 \mu \mathrm{M}$ Simvastatin $+5 \mu \mathrm{M}$ Doxorubicin, (C) $5 \mu \mathrm{M}$ Simvastatin $+10 \mu \mathrm{M}$ Doxo-

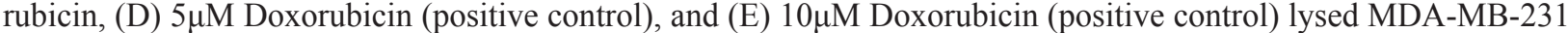
breast cancer cell morphology were seen. (F) Negative control of MDA-MB-231 breast cancer cell lines were $80-90 \%$ confluent after incubation for 48 hours.

to negative controls. Increasing the dose of Simvastatin caused an increase in cell death in both cancer cell lines (dose-dependent manner and time-dependent manner) (Table 1).

The cytotoxic effect of Simvastatin on MCF-7 and MDA-MB-231 cancer cells can be seen using the MTT assay. The results showed that Simvastatin treatment with an incubation period of 24,48 , and 72 hours has cytotoxic properties and triggered MCF-7 cell death. Half-maximal inhibitory concentration $\left(\mathrm{IC}_{50}\right)$ values calculated from the results were $30.6 \mu \mathrm{M}(\mathrm{P}<0.001), 8.9 \mu \mathrm{M}(\mathrm{P}<0.001)$,

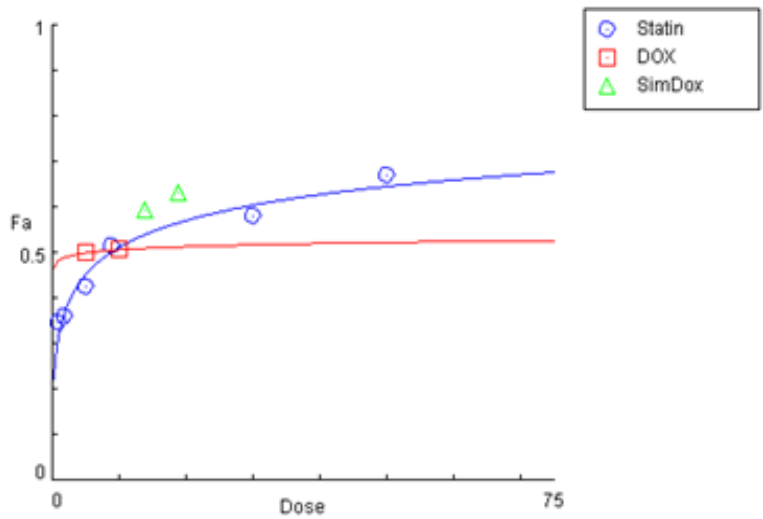

Figure 8. Combination of the Simvastatin with Doxorubicin Induces Synergism in MCF-7 cells. MCF7 cells were treated as indicated concentration with Simvastatin only, Doxorubicin only, and SimvastatinDoxorubicin Combination for 48 hours. Combination index was analyzed using Compusyn Software. and $1.1 \mu \mathrm{M}(\mathrm{P}<0.001)$ respectively for each incubation period. Simvastatin is also shown to have cytotoxic effects on MDA-MB-231 cells which caused cell death with an incubation period of 24, 48, and 72 hours. Half-maximal inhibitory concentration $\left(\mathrm{IC}_{50}\right)$ values calculated from the results were $26.7 \mu \mathrm{M}(\mathrm{P}<0.001), 4.5 \mu \mathrm{M}(\mathrm{P}<0.001)$, and $1.7 \mu \mathrm{M}(\mathrm{P}<0.001)$ respectively for each incubation period. Declining $\mathrm{IC}_{50}$ values with longer incubation period showed that the dose needed to cause the death of both breast cancer cells will be lower in prolonged

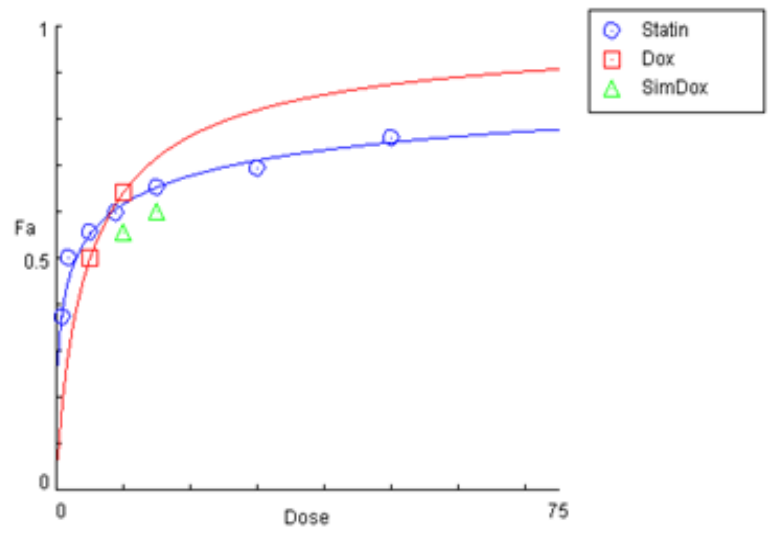

Figure 9. Combination of the Simvastatin with Doxorubicin Induces Antagonism in MDA-MB-231 Cells. MDA-MB-231 cells were treated as indicated concentration with Simvastatin only, Doxorubicin only, and Simvastatin-Doxorubicin Combination. for 48 hours. Combination index was analyzed using Compusyn Software. 
Table 3. Cell Viability and Cell Death in MCF-7 Breast Cancer Cell Lines Treated with Simvastatin for 48 hours. Results were obtained from Trypan Blue test.

\begin{tabular}{lcc}
\hline Concentration $(\mu \mathrm{M})$ & Cell Viability $(\%)$ & Cell Death $(\%)$ \\
\hline Sim1 & 65.4 & 34.6 \\
Sim2 & 63.6 & 36.2 \\
Sim5 & 57.3 & 42.7 \\
Sim9 & 48.5 & 51.5 \\
Sim30 & 41.9 & 58.1 \\
Sim50 & 32.8 & 67.2 \\
Dox5 & 50.0 & 50.0 \\
Dox10 & 49.2 & 50.7 \\
Sim9+Dox5 & 40.6 & 59.4 \\
Sim9+Dox10 & 36.6 & 63.4 \\
Control Cell & 96.4 & 3.6 \\
\hline
\end{tabular}

incubation period, such as 48 and 72 hours, compared to only 24 hours. These results indicate that the longer the cell is exposed to Simvastatin, cell death will be more prominent (Table 2) (Figure 1).

$\mathrm{IC}_{50}$ results from this study also indicate that MDA-MB-231 cell death required a lower dose of Simvastatin compared to MCF-7 cells. This happens because p53 in MCF-7 and MDA-MB-231 cells have a synergistic contribution to the effect of cell death. MDA-MB-231 cells have a p53 mutation, so MDA-MB-231 cells and thus are more susceptible to cell death than MCF-7 cells. This happened, presumably because the damage that occurred in the DNA of MDA-MB-231 cells at various stages of the cell cycle cannot be repaired by the mutated p53 (Rezano et al., 2013).

The effect of Simvastatin on the increase in both cell death can be proven by the similarity of effects between the treatment of Simvastatin and Doxorubicin, which were a conventional chemotherapy. The effect on the increase in cell death that was not significantly different $(\mathrm{P}>0.05)$ between cells treated with Simvastatin and cells treated with Doxorubicin showed that both drugs had the same effect. The results showed that treatment of Simvastatin at an indicated dose of $5,10,20$, and $50 \mu \mathrm{M}$ for 24 and 48 hours on MDA-MB-231 cells showed no effect on the number of cell death that was not significantly different from Doxorubicin-treated cells at a dose of $5 \mu \mathrm{M}$ and $10 \mu \mathrm{M}(\mathrm{P}>0.05)$. The administration of Simvastatin at a dose of $50 \mu \mathrm{M}$ for 24 hours and a dose of $5 \mu \mathrm{M}, 10 \mu \mathrm{M}$, and $20 \mu \mathrm{M}$ for 48 hours on MCF-7 cells showed no significant difference in efficacy when compared to Doxorubicin at a dose of $5 \mu \mathrm{M}$ and $10 \mu \mathrm{M}(\mathrm{P}>0.05)$. MDA-MB-231 cells that were treated with Simvastatin at a dose of 3, 5 and 10 $\mu \mathrm{M}$ for 72 hours also showed no significant effect against cells treated with Doxorubicin at a dose of $5 \mu \mathrm{M}$ and 10 $\mu \mathrm{M}(\mathrm{P}>0.05)$. The administration of Simvastatin at a dose of $10 \mu \mathrm{M}$ on MCF-7 cells for 72 hours showed an effect that was also not significantly different from cells given Doxorubicin at a dose of $5 \mu \mathrm{M}(\mathrm{P}>0.05)$.

The effect of Simvastatin on MCF-7 and MDA-MB-231 cell death can be strengthened by trypan blue exclusion
Table 4. Cell Viability (\%) and Cell Death (\%) in MDA-MB-231 Breast Cancer Cell Lines Treated with Simvastatin for 48 hours. Results were obtained from Trypan Blue test.

\begin{tabular}{lcc}
\hline Concentration $(\mu \mathrm{M})$ & Cell Viability $(\%)$ & Cell Death $(\%)$ \\
\hline Sim1 & 62.4 & 37.5 \\
Sim2 & 50.0 & 50.0 \\
Sim5 & 44.4 & 55.6 \\
Sim9 & 40.1 & 59.8 \\
Sim15 & 34.5 & 65.4 \\
Sim30 & 30.3 & 69.6 \\
Sim50 & 23.8 & 76.2 \\
Dox5 & 50.0 & 50.0 \\
Dox10 & 35.7 & 64.3 \\
Sim5+Dox5 & 44.4 & 55.6 \\
Sim5+Dox10 & 40.0 & 60.0 \\
Control Cell & 95.0 & 5.0 \\
\hline
\end{tabular}

test. The $\mathrm{IC}_{50}$ of Simvastatin which was $8.9 \mu \mathrm{M}$ and 4.5 $\mu \mathrm{M}$ for MCF-7 and MDA-MB-231 had a very significant effect on cell death when incubated for 48 hours $(\mathrm{P}<0.001)$. The effect can also be proven by comparing with the positive control. The results showed that the administration of Simvastatin with $\mathrm{IC}_{50}$ dose until $50 \mu \mathrm{M}$ and combination drug caused cell death on both cancer cell lines $(\mathrm{P}<0.05)$.

The death of MCF-7 and MDA-MB-231 cell lines also proven by microscopic examination. Morphological changes that were unique to cancer cell lines such as cell shrinking, cell rounding, cell detaching, and cell lysis were displayed when cells were treated with Simvastatin at a dose of $\mathrm{IC}_{50}$ until dose of $50 \mu \mathrm{M}$ and combination drug on MCF-7 (Table 3, Figure 4, Figure 5) and MDA-MB-231 (Table 4, Figure 6, Figure 7). Microscopic images also showed an evidence of cell death, with apoptogenic cell counting values indicate significant cell death $(\mathrm{P}<0.05)$.

It has been reported (Liao, 2002) that cancer cells usually exhibit elevated levels of HMG-CoA and low-density lipid receptor to satisfy their demand for isoprenoid and lipids, suggesting them to be more sensitive than normal cells to statins. Moreover, master mevalonate pathway genes, HMGCR and HMGCS2 were also overexpressed in breast cancer tissue at the level of gene transcript and protein. Therefore, these clues strongly indicated high dependency of breast cancer on mevalonate pathway (Ponten et al, 2011; Bai et al, 2019).

The effect of Simvastatin on MCF-7 and MDA-MB-231 cells is likely due to the inhibition of the mevalonate pathway which subsequently inhibited the production of various end products, such as cholesterol, dolichol, ubiquinone, isopentenyl adenine, geranylgeranyl pyrophosphate (GGPP) and farnesyl pyrophosphate (FPP). These were important components of various cell functions such as cell proliferation, differentiation, and survival, both for normal cells and cancer cells. Thus, the administration of Simvastatin will result in cell cycle arrest, cell proliferation inhibition, and even cell death via apoptosis and necrosis (Chan et al., 2003; Moon and 
Bogle, 2010; Ostad and Parsa, 2011; Wang et al., 2016; Putra et al., 2017). The process can be explained in previous studies on lung and prostate cancer cell treatment with Simvastatin (Goc et al., 2012; Wang et al., 2018).

In previous studies, it was proven that the administration of Simvastatin to cancer cells will reduce the production of GGPP and FPP and thus caused apoptosis (Goc et al., 2012; Wang et al., 2016; Putra et al., 2017), anti-proliferative effects (Feldt et al., 2015; Wang et al., 2015; Beckwitt et al., 2018), and deactivation of the signaling pathway in breast cancer cells (Wang et al., 2016; Beckwitt et al., 2018). The reduced production of GGPP and FPP will also decrease RAS translocation from cytoplasm to cell membranes, causing RAS signal transduction to decrease or even stop. This resulted in the inactivation of two important pathways in cell proliferation, the MAPK pathway, and the PI3K/Akt pathway. Statin drugs also inhibited cell proliferation by decreasing cyclin D1 expression and increasing p27 expression which can cause cell cycle arrest in G1 phase. Statins can also cause cell apoptosis through intrinsic and extrinsic signaling pathways by increasing caspase 9,10 , 8, and 3 division (Goc et al., 2012).

Simvastatin mediated effects on breast cancer cell viability and cell death was similar to the effects of doxorubicin. Our data confirmed that both simvastatin and doxorubicin significantly induced both cell death and lysed cell morphology. Doxorubicin has shown great efficacy in cancer cell killing but the emergence of drug resistance and adverse effects are major limitation for successful breast cancer treatment. The combination treatment in this study was then interpreted based on the classification of drug interactions, in which $\mathrm{CI}<1$ showed synergism, $\mathrm{CI}=1$ showed additive effect and CI $>1$ showed an antagonistic effect (Chou, 2010). The results from combination treatment in MCF-7 cancer cell lines showed a synergistic effect, unlike the effect on MDA-MB-231 cancer cell lines which showed an antagonistic effect. This could be explained by the different drug interactions that occur in these cell lines due to the different amounts of drug receptors of these cell lines, resulting in receptor competition. In MDA-MB-231, the effect of combination treatment is more antagonistic with increases of doxorubicin concentration, unlike in MCF-7. Various biological mechanism involves in cancer treatment including drug resistance. The key effect of drug resistance is the cellular drug transporter system that may involve in triple negative breast cancer MDA-MB-231 cells.

Moreover, recent study shows that simvastatin increase oxidative stress and DNA damage by upregulating NRF1 and mIR-140 expression in breast cancer cells (Bai et al., 2019). The response to DNA damage has a profound effect on tumor chemosensitivity and chemoresistance. Signaling pathways have evolved to stop cell cycle following DNA damage to allow time for DNA repair. If the DNA damage is too extensive, the cells will undergo apoptosis. The relationship between cell cycle arrest and apoptosis following chemotherapy is complex and dependent on both the chemotherapy used and the molecular phenotype of the tumor cells.
Having a promising data of Simvastatin in breast cancer cells, further study is conducting to advance analyze molecular mechanism of this drug inhibiting cell proliferation and inducing cell death via apoptosis.

In conclusion, our data showed that Simvastatin may have potential anti-cancer activity in breast cancer cells, with potent cytotoxic effect resulting in cell death and may serve as chemotherapeutic agent for treatment of breast cancer, possibly in combination with chemotherapy.

\section{Acknowledgments}

We would like to thank all people involved in this study, especially to Ms. Tenny Putri and Ms. Nurul Qomarilla for technical assistance during experiments at the Laboratory of Advanced Biomedicine Cell Culture and Cytogenetic, Faculty of Medicine, Universitas Padjadjaran; Mrs. Pratiwi, Apt. from Dr. Hasan Sadikin Hospital, Bandung who provided chemotherapy drugs.

\section{Funding Statement}

This work was supported by Internal Grant of Universitas Padjadjaran 2019 (Riset Kompetensi Dosen Unpad).

\section{Conflict of Interests}

The authors declare that they have no conflict of interests regarding researches, authorship, and/ or publication of this article. None of the authors was affiliated with the companies mentioned in this article.

\section{References}

Abdel-Hameed ES, Bazaid SA, Shohayeb MM, El-Sayed MM, El-Wakil EA (2012). Phytochemical studies and evaluation of antioxidant, anticancer and antimicrobial properties of Conocarpus erectus L. growing in Taif, Saudi Arabia. Eur J Med Plants, 2, 93-112.

Bai F, Yu Z, Gao X, et al (2019). Simvastatin induces breast cancer cell death through oxidative stress up-regulating miR-140-5p. Aging, 11, 3198-3219.

Bardou M, Barkun A, Martel M (2010). Effect of statin therapy on colorectal cancer. Gut, 59, 1572-85.

Beckwitt CH, Shiraha K, Wells A (2018). Lipophilic statins limit cancer cell growth and survival, via involvement of Akt signaling. PLoS One, 13, 1-22.

Beckwitt CH, Brufsky A, Oltvai ZN, Wells A (2018). Statin drugs to reduce breast cancer recurrence and mortality. Breast Cancer Res, 20, 144.

Bray F, Ferlay J, Soerjomataram I, et al (2018). Global Cancer Statistics 2018: GLOBOCAN estimates of incidence and mortality worldwide for 36 cancers in 185 countries. $C A$ Cancer J Clin, 68, 394-424.

Campbell MJ, Esserman LJ, Zhou Y, et al (2006). Breast cancer growth pevention by statins. Cancer Res, 66, 8707-14.

Cardwell CR, Hicks BM, Hughes C, Murray LJ (2015). Statin use after diagnosis of breast cancer and survival: a population-based cohort study. Epidemiology, 26, 68-78.

Chan KKW, Oza AM, Siu LL (2003). The statins as anticancer agents. Clin Cancer Res, 9, 10-9.

Chou TC (2010). Drug combination studies and their synergy quantification using the Chou-Talalay method. Cancer Res, 70, 440-6.

Crosbie J, Magnussen M, Dornbier R, Iannone A, Steele TA

Asian Pacific Journal of Cancer Prevention, Vol 22 
(2013). Statins inhibit proliferation and cytotoxicity of a human leukemic natural killer cell line. Biomark Res, 1, 33.

Desai P, Lehman A, Chlebowski RT, et al (2015). Statins and breast cancer stage and mortality in the Women's Health Initiative. Cancer Causes Control, 26, 529-39.

Feldt M, Bjarnadottir O, Kimbung S, et al (2015). Statin-induced anti-proliferative effects via cyclin D1 and p27 in a window-of-opportunity breast cancer trial. $J$ Transl Med, 13, 1-11.

Fong CW (2014). Statins in therapy: Understanding their hydrophilicity, lipophilicity, binding to 3-hydroxy-3methylglutaryl-CoA reductase, ability to cross the blood brain barrier and metabolic stability based on electrostatic molecular orbital studies. Eur J Med Chem, 85, 661-74.

Gazzerro P, Proto MC, Gangemi G, et al (2012). Pharmacological actions of statins: a critical appraisal in the management of cancer. Pharmacol Rev, 64, 102-46.

Ghavami S, Mutawe MM, Hauff K, et al (2010). Statin-triggered cell death in primary human lung mesenchymal cells involves p53-PUMA and release of Smac and Omi but not cytochrome C. Biochim Biophys Acta, 4, 452-67.

Goc A, Kochuparambil ST, Al-Husein B, et al (2012). Simultaneous modulation of the intrinsic and extrinsic pathways by simvastatin in mediating prostate cancer cell apoptosis. BMC Cancer, 12, 409.

Holliday DL, Speirs V (2011). Choosing the right cell line for breast cancer research. Breast Cancer Res, 13, 215.

Hu M, Cheung BMY, Tomlinson B (2012). Safety of statins: an update. Ther Adv Drug Saf, 3, 133-44.

Kumar V, Abbas A, Aster J (2014). Robbins and Cotran Pathologic Basis of Disease. In 'Neoplasia', 9th ed. Elsevier Inc, Philadelphia, pp 1051-7.

Liao JK (2002). Isoprenoids as mediators of the biological effects of statins. J Clin Invest, 110, 285-8.

Moon JC, Bogle RG (2006). Switching Statin: Using generic simvastatin as first line could save £2bn over five years in England. BMJ, 332, 1344-5.

Moongkarndi P, Kosem N, Kaslungka S, et al (2004). Antiproliferation, antioxidation and induction of apoptosis by Garcinia mangostana (mangosteen) on SKBR3 human breast cancer cell line. J Ethnopharmacol, 90, 161-6.

Munawar M, Hartono B, Rifqi S (2013). LDL cholesterol goal attainment in hypercholesterolemia: Cepheus Indonesian survey. Acta Cardiol Sin, 29, 71-81.

Ostad SN, Parsa M (2011). Breast Cancer from Molecular Point of View: Pathogenesis and Biomarkers. In 'Focusing Tumor Microenvironment, Stem Cells, and Metastasis', Ed Gunduz M. InTech Open, Shanghai, pp 103-25.

Pantziarka P, Pirmohamed M, Mirza N (2018). New uses for old drugs: Low cost generics are an untapped source of therapeutic innovation. $B M J, \mathbf{3 6 1}, \mathrm{k} 2701$.

Perou CM, Borresen-Dale AL (2011). Systems biology and genomics of breast cancer. Cold Spring Harb Perspect Biol, 3, 1-17.

Putra B, Wahyuningsih MSH, Sholikhah EN (2017). Cytotoxic activity of simvastatin in T47D breast cancer cell lines and its effect on cyclin D1 expression and apoptosis. J Med Sci, 49(2), 47-55.

Rezano A, Kuwahara K, Yamamoto-Ibusuki M, et al (2013). Breast cancers with high DSS1 expression that potentially maintains BRCA2 stability have poor prognosis in the relapse-free survival. BMC Cancer, 13, 562.

Wang F, Liu W, Ning J, et al (2018). Simvastatin suppresses proliferation and migration in Non-small Cell Lung Cancer via Pyroptosis. Int J Biol Sci, 14, 406-17.

Wang G, Cao R, Wang Y, et al (2016). Simvastatin induces cell cycle arrest and inhibits proliferation of bladder cancer cells via PPAR- signalling pathway. Sci Rep, 6, 35783.

Wang T, Seah S, Loh X, et al (2016). Simvastatin-induced breast cancer cell death and deactivation of PI3K/Akt and MAPK/ ERK signaling are reversed by metabolic products of the mevalonate pathway. Oncotarget, 7, 2532-44.

This work is licensed under a Creative Commons AttributionNon Commercial 4.0 International License. 